\title{
Infarto agudo do miocárdio em paciente jovem: relato de caso
}

\author{
Acadêmica: Deborah Yukiko Otto \\ Orientadores: Fabiana Hanna Rached, Cibele Larrosa Grarzillo
}

Introdução: O Infarto Agudo do Miocárdio (IAM) é uma entidade relativamente rara em jovens; nesta população, a apresentação e o mecanismo do IAM podem ser consideravelmente distintos daqueles comumente vistos em pacientes idosos, nos quais a doença aterosclerótica coronariana (DAC) é a principal etiologia. Infelizmente, a patogenia do processo em jovens não está completamente esclarecida, embora haja hipóteses a respeito.

Objetivo: Relatamos a seguir o caso de um paciente jovem com história de dois infartos do miocárdio, sem antecedentes familiar ou pessoal que sugerissem doença arterial coronariana precoce.

Relato do caso: Paciente do sexo masculino, na ocasião do primeiro evento com 16 anos, natural do Maranhão e procedente do Guarujá - SP, previamente assintomático, com história de dois episódios de IAM ocorridos em 2010 e 2012 . Iniciou acompanhamento em hospital terciário em XXXX. Na ocasião dos eventos, descrevia dor precordial anginosa típica com duração de 30 minutos, e negou tabagismo e uso de drogas ilícitas. Em primeira avaliação ambulatorial, trouxe resultados de eletrocardiograma (elevação de segmento ST lateral alto na primeira ocorrência e sem supra de ST na segunda) e cineangiocoronariografia que não identificou aterosclerose coronariana. De antecedentes familiares, refere apenas uma tia com trombose venosa e lúpus eritematoso sistêmico e um avô que morreu aos 60 anos por IAM. Evoluiu com episódios de dor torácica não anginosa com teste ergométrico negativo em 2012, 2013 e 2014 e exames de ecocardiograma sem alterações significativas, demonstrando função ventricular normal. Nega tabagismo e uso de drogas ilícitas. Como parte da investigação de causas de IAM em jovem, foram solicitados pesquisa para síndrome antifosfolípide (SAF), perfil lipídico, valores de proteína $\mathrm{C}$, homocisteína, vitamina B12 e coagulograma, todos com resultados dentro da normalidade. Entretanto, foi identificada elevação importante dos níveis de Lp(a) (119,00 mg/dL; valor de referência < 30,0 mg/dL).

Em jovens, na ausência de uso de drogas ilícitas, destacam-se como causa do IAM patologias como vasculite, dissecção de coronária, aneurisma e hipercoagulabilidade. No presente caso, o paciente não apresentava lesão aterosclerótica e o único marcador alterado era o valor da lipoproteína (a) [Lp(a)].

A Lp (a) é uma partícula semelhante ao LDL e que contém em sua estrutura a apolipoproteína (a) [apo (a)]; sua concentração sérica é, sobretudo, determinada geneticamente, de acordo com o polimorfismo do gene de LPA herdado. A Lp (a) parece ter papel relevante na aterosclerose e em processos trombóticos, de acordo com os seguintes mecanismos: 1) homologia de domínios da apo (a) com domínios do plasminogênio, competindo com esta pró-enzima e impedindo sua ação fibrinolítica; 2) aumento da produção do Inibidor do Ativador do Plasminogênio tipo 1 (PAI-1); 3) ligação de isoformas do Lp (a) à fibrina, inibindo a formação de plasmina; 4) inativação de inibidores do fator tissular. Assim, haveria um estado de hipercoagulabilidade que poderia ajudar a justificar o quadro deste paciente. 